

\section{Equipe de Revisão Final de Normas e de Linguagem}

Dr. Marcelo Pessoa, BRAZIL

Arianne Moraes - Depto. de Marketing, BRAZIL

Yago Patranis - Assistente de Editoração, INDIA

\section{Revisão de Diagramação e Arte}

Dr. Marcelo Pessoa, BRAZIL

\section{Capa}

Autor: Compilado de capas das obras de Monteiro Lobato

Título: Homenagem ao autor, que entrou em domínio público, a partir de janeiro de 2019

Imagens disponíveis: http://enciclopedia.itaucultural.org.br/pessoa59/monteiro-lobato/obras?p=1.

\section{Impressão por demanda e hospedagem eletrônica do volume 7}

Revista AKEDIA - Grupo SIC - UEMG / CNPq

\section{Periódico Nacional Indexado por}

Google Scholar

Diadorim/IBICT

Latindex

Orcid Connecting Research and Researchers

Researcher Id

Claryvate Analytics

Periódico Licenciado e também Indexado por

Creative Commons - Atribuição 4.0 Internacional

\section{Editor Corporativo}

MPEducacional

\section{Editor-Chefe}

Prof. Dr. Marcelo Pessoa

\section{Conselho Editorial}

Dr. Dionísio Vila Maior (UAL, Lisboa)

Dr. Rodrigo Ney Millan (UEMG, Frutal)

Dr. Andrés Alberto Donoso Romo (UPLA, Chile)

Dr. Allynson Takehiro Fujita (UEMG, Frutal)

Dra. Cintia Camargo Vianna (UFU, Uberlândia)

Dr. Marcelo Pessoa (UEMG, Frutal)

Dr. Jorge Pedro Sousa (Universidade do Porto, Portugal)

Dra. Daniella Soares Portela (UEMG, Frutal)

Dra. Jociene Carla Bianchini Ferreira (UFMT, Mato Grosso)

Dr. André Vinicius Martinez Gonçalves (IFG, Goiás)

Dra. Cristiane Pimentel Neder (UEMG, Frutal)

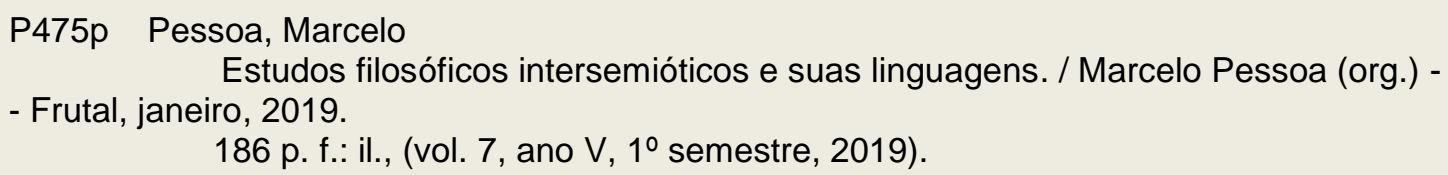

ISSN 2447-7656

DOI NUMBER 10.33726

1. Produção científica. 2. Homem. 3. Cultura. 4. Sociedade I. Pessoa, Marcelo. II. UEMG / CNPq. III. Título. 


\section{SUMÁRIO}

\section{ARTIGOS}

(NOTA: A ORIGINALIDADE DOS TEXTOS É DE RESPONSABILIDADE DE SEUS AUTORES E AUTORAS. CABE À EQUIPE EDITORIAL DA REVISTA AKEDIA, APENAS A REALIZAÇÃO DOS SER VIÇOS DE EDITORAÇÃO E POSTAGEM ELETRÔNICA)

EDITORIAL PARA O VOLUME 7 .05

PREFÁCIO PARA O VOLUME 7 - A IMPORTÂNCIA DE LOBATO PARA O BRASIL 07

1. BARBOSA, MAYLLA LIENCKVITZ; SOUZA, POLIANA TOMAZ; VILELA, DANILO VIEIRA - OS IMPACTOS DA REFORMA TRABALHISTA PARA A SAÚDE DO TRABALHADOR .09

2. PAGLIONE, CHRISTIANE; LEALI, CLAITON ANTONNIO; CRUZ SILVA, JANAÍNA MENDONÇA DA; TRAJANO, ANA RITA CASTRO - A IMPORTÂNCIA DA QUALIFICAÇÃO PROFISSIONAL PARA A GESTÃO PÚBLICA MUNICIPAL E A IMPLEMENTAÇÃO DO PLANEJAMENTO ESTRATÉGICO SITUACIONAL

PES.

3. PESSOA, MARCELO - POR FORA SOU GOTEIRA, POR DENTRO, TEMPESTADE. 48

4. CARVALHO, CELSO ALMEIDA DE - COMO O JAPÃO CRIOU O MERCADO DE FUTUROS 64

5. LOBATO, MONTEIRO OALTO - CÁTULO
SACIZADA CAPÍTULO A 6. CARVALHO, CELSO ALMEIDA DE - O ENSINO DO EMPREENDEDORISMO NAS ESCOLAS: O QUE NOS SEPARA DO MUNDO.. 7. MENEZES, ELENICE SALES FELICIANO \& LÉPORE, PAULO EDUARDO - EDUCAÇÃO
AMBIENTAL:
URÁTICA 7. MENEZES, ELENICE SALES FELICIANO \& LÉPORE, PAULO EDUARDO - EDUCAÇÃO
AMBIENTAL:
URÁTICA 7. MENEZES, ELENICE SALES FELICIANO \& LÉPORE, PAULO EDUARDO - EDUCAÇÃO
AMBIENTAL:
PRÁTICA SUSTENTÁVEL .. .97

8. DANIEL, DEVANIR DONIZETI \& MENEZES, ELENICE SALES - CONTROLE DA CIGARRINHA NA RAIZ DA CANA-DEAÇÚCAR

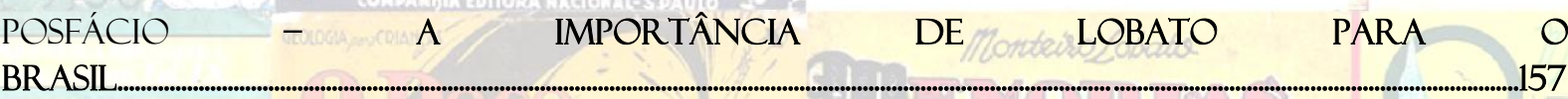

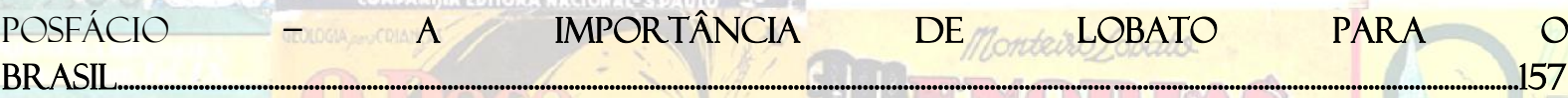

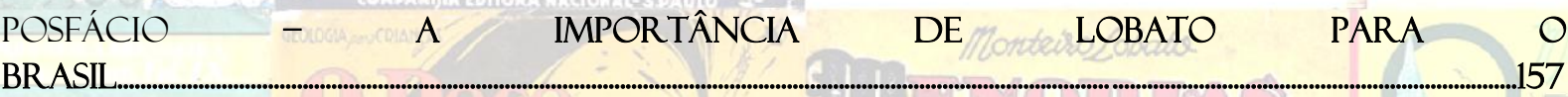
9. FONSECA, DAVID \& PESSOA, MARCELO - MODELO DE GESTÃO DAS BARBEARIAS MODERNAS. .159

10. SOUZA, MARCELA FERNANDA DA PAZ DE - ABORDAGENS DE GÊNERO: INDICAÇÕES INTERACIONISTA, INSTITUCIONAL E DE ESTRUTURA SOCIAL 


\title{
ABORDAGENS DE GÊNERO: INDICAÇÕES INTERACIONISTA, INSTITUCIONAL E DE ESTRUTURA SOCIAL
}

\author{
SOUZA, Marcela Fernanda da Paz de ${ }^{1}$
}

\section{DOI NUMBER: 10.33726/akedia2447-7656v7a52019p165-186}

RESUMO: O artigo apresenta as abordagens de gênero, com o objetivo de compreender como as desigualdades entre homens e mulheres são construídas socialmente e reverberam seus efeitos sobre um amplo escopo da vida humana, como as relações entre gênero e mercado de trabalho. Durante décadas, os estudos das Ciências Humanas se dedicaram a desmitificar o embasamento desta assimetria, a qual marcada por um suposto determinismo biológico. As desigualdades entre homens e mulheres e o empoderamento masculino não podem ser analisados de forma universal, pois há variações conforme os contextos cultural e social específicos. Assim, compreende-se ser relevante analisar as diferenças entre sexo, sexualidade e gênero, respectivamente, com as características fisiológicas e as capacidades reprodutivas: a sexualidade inerente às capacidades associadas ao sexo e o gênero com uma construção social. A construção deste estudo baseou-se nas referências bibliográficas dos recentes estudos sobre as desigualdades e interseccionalidades entre homens e mulheres.

PALAVRAS-CHAVE: Gênero, Empoderamento, Desigualdades Sociais.

ABSTRACT: The article presents the gender approaches with the objective of understanding how the inequalities between men and women are socially constructed and reverberate their effects on a wide scope of human life, such as the relations between gender and the labor market. For decades, studies of the Humanities have to demystify the basement of this asymmetry, which is marked by an alleged biological determinism. The inequalities between men and women and the male empowerment can't be analyzed in a universal way, because there are variations according to the specific cultural and social contexts. Thus, it is understood to be relevant to analyze the differences between sex, sexuality and gender, respectively, with physiological characteristics and reproductive capacities: the sexuality inherent in the capacities associated with sex and gender with a social construction. This study was based on the bibliographical references of recent studies on and interseccionalidades inequalities between men and women.

KEYWORDS: Gender, Empowerment, Social Inequalities.

\footnotetext{
${ }^{1}$ Bacharel em Comunicação Social (UFJF) - Jornalismo. Doutora pelo Programa de Pós-Graduação em Ciências Sociais (UFJF). Pós-doutora em Estudos Urbanos e Regionais (UFRN). Profa. Adj. do Curso de Bacharelado em Jornalismo da UEMG - Unidade Frutal.
} 


\section{INTRODUÇÃO}

O artigo apresenta a contribuição teórica das relações de gênero no âmbito da "categorização de sexo" em uma perspectiva interacionista. Os eixos centrais desta análise são: a) a etnometodologia - "fazendo gênero"; b) a teoria das características de status e gênero e c) a homifilia ${ }^{2}$.

Propõe-se que a categoria de sexo se tornou um código nas interações e balizador dos critérios de diferenciações dos grupos. Como resultado, há diferentes apropriações das condições sexuais individuais por parte de homens e de mulheres no mercado de trabalho, na alocação de recursos e na divisão sexual do trabalho.

As contribuições que nos auxiliaram na compreensão desta abordagem, advêm da produção de Candace West e Don Zimmerman, Erving Goffman e Amy Wharton.

Numa breve análise dos estudos relacionados à Sociologia Clássica e de Gênero, é fácil notar que ambas as vertentes teóricas trazem à tona uma abordagem das condições sexuais do indivíduo elencadas sob o estatuto de instituição social. Assim, esta instituição, vista sob este aspecto, é construto sociocultural que está suscetível a mudanças e transformações, não apenas pelo caráter imutável e não passível de reconstrução, do modo como se constituiu teoricamente em meados do século XX, mas, sobretudo, pelo modo como se devem compreender as concepções de gênero. Isto é, como uma instituição social apta a transformações, o que implica em considerar que não há uma obrigatoriedade na reprodução das desigualdades entre homens e mulheres nas escolas, no sistema político, nas famílias e no mercado de trabalho, mas, bem ao contrário disso, ao invés de repercutir tais anomalias, esta instituição social cuida, ainda, de inibir, combater anacronismos, aparando arestas presentes na "cultura" das diferenças.

Desse modo, a reflexão que ora se impõe, discorrerá sobre doze características de várias instituições sociais que perpassam as relações de gênero. Ter-se-á como principal referência desta discussão, o pensamento de Patrícia

\footnotetext{
${ }^{2}$ Trata-se de palavra ainda não dicionarizada e nem elencada pelo VOLP - Vocabulário Ortográfico da Língua Portuguesa, documento ortográfico editado pela $\mathrm{ABL}$ - Academia Brasileira de Letras. Contudo, nesta condição de neologismo, o termo "homifilia" tem sido utilizado e tido como de "uso corrente", associado ao vocábulo "homofobia".
} 
Martin, que à sua contribuição será somada a de Amy Wharton e de Anthony Giddens.

A compreensão da sexualidade como instituição social implica assumir as consequências que esta instituição deposita sobre todo o status quo da contingência de gêneros. Além disso, à medida que os indivíduos são percebidos conforme a sua raça, etnia, todos estes atributos contribuem para um redimensionamento do status individual que se impõe como prioritário sobre o coletivo.

Ao lado disso, vemos que o valor do "reconhecimento" social é fundamental no rito de autoafirmação do indivíduo, uma vez que quem não o tem, muitas vezes, é obrigado a ter uma condição de vida insustentável. reconhecimento per se é uma noção fundamental ao se pensar, por exemplo, no posicionamento da mulher nas diversas expressões de status social e no mercado de trabalho. Ter o reconhecimento e se autorreconhecer implica em superação de desigualdades pontuais, elementos tidos como altamente relevantes nos escritos de Erik Olin Wright, Judith Butler, Judith Lorber e Susan Farrel.

Os posicionamentos sexuais são estruturas sociais presentes nos lugares comuns da vida do indivíduo. Por meio de uma abordagem integrativa, se podem abranger quatro eixos teóricos consagrados pelos estudos da Sociologia de Gênero: a) a primeira tradição indica as interpretações com raízes individuais e biossociais; b) a segunda, situa o comportamento dos homens e das mulheres determinados por fatores como a socialização e o controle social; c) a terceira tradição demonstra gênero como o resultado das práticas da interação nas relações sociais, e essa tradição se afasta das prerrogativas da primeira tradição; e, d) a quarta tradição é a abordagem integrativa com um sistema de estratificação socialmente construído e em um nível de análise das estruturas políticas e econômicas.

Esta última é chamada integrativa, visto que engloba o nível interacional, individual, expectativa cultural e 0 domínio institucional. O ponto central de Bárbara Risman nessa abordagem é o de compreender quais são os mecanismos construtores da desigualdade e, acima de tudo, como desconstruí-los para criar uma vida social justa, promovendo os movimentos de transformação, momento da discussão em que nos alicerçamos, também, nas obras de Candace West, Don Zimmerman, Judith Lorber, Richard Udry, Robert Connell, Sandra Bem. 


\section{A PROPOSTA INTERACIONISTA}

As pesquisadoras West e Zimmerman $(1987,1991)$ propuseram o estudo das relações de gênero, a partir da abordagem interacionista. A linha central das perspectivas que compõem esta abordagem é a etnometodologia ("fazendo gênero"); a teoria das características de status e gênero, e a homifilia - que trata da categorização de sexo.

Um ponto essencial para as autoras é a legitimação dos arranjos sociais baseados na formação da "categoria de sexo". Conforme Goffman $(1956,1977)$, para as sociedades de diversas temporalidades, o sexo, enquanto categoria tornou-se a base de um código fundamental, cujas interações e estruturas sociais são construídas. É, por assim dizer, um código individual que também estabelece as concepções individuais relativas à natureza humana.

A categoria "sexo", desse modo, é um importante elemento no critério de diferenciação social e acarreta importantes consequências para os indivíduos ou grupos. Um exemplo disso é a alocação assimétrica de recursos e de poder, no universo privado e/ou público, e nas relações interpessoais que têm origem nas distinções ancoradas na sexualidade. A disposição de gênero faz com que os arranjos sociais sejam formas legítimas de organizar a vida social. As assimetrias geradas podem ser visíveis enquanto disposições duradouras. A ordem social é o lócus de sobrevivência da ordem natural (SOUZA, 2010; WHARTON, 2005):

O gênero é um poderoso artifício ideológico, que produz, reproduz, e legitima as escolhas e os limites que são predicados sobre a categoria sexo. Uma compreensão de como o gênero é produzido nas situações sociais permitirá o esclarecimento do arcabouço interacional da estrutura social e dos processos de controle social que o sustentam (WEST; ZIMMERMAN, 1987 p. 147).

No argumento etnometodológico ("fazendo gênero"), a centralidade da reflexão gira em torno de se analisar o fenômeno "gênero", a partir de uma realidade rotineira, metódica e recorrente presente nas relações sociais e nas reações dos homens e das mulheres, conforme a realidade cultural e histórica em que estão envolvidos. Sob este ponto de vista, homens e mulheres são reféns sociais do 
"fazendo gênero", cujo processo envolve uma complexa percepção socialmente orientada, somada aos processos de interação e à micropolítica.

As atividades ganham contornos das expressões da natureza masculina e feminina. Se gênero é uma construção social, então, a atenção deve se ater à interação e, finalmente, ao âmbito institucional (WEST; ZIMMERMAN, 1991).

Para West e Zimmerman (1991), a expressão "fazendo gênero" implica na criação de diferenças entre os sexos, aquelas que não são naturais ou biológicas, e reforçam a sua essencialidade. Quaisquer encontros sociais estão potencialmente voltados para a problemática de gênero. Deve-se considerar, portanto, que os indivíduos apresentam diversas identidades sociais que se sobressaem de acordo com a situação.

Uma mesma pessoa pode assumir distintos papeis, ao mesmo tempo e em diferentes momentos, mas, se é sempre homem ou mulher e a identificação apresenta um recurso disponível para "fazer gênero", emerge uma infinidade de possibilidades sexuais intercambiantes segundo a sugestão de cada circunstância. Há situações sociais organizadas rotineiramente que demonstram e celebram os comportamentos condicionados a uma ou outra categoria de sexo e os indivíduos estão situados no processo interacional em que estão inseridos, ainda que uma pessoa pertencente a uma determinada categoria atue como participante de outra, esta ordem é desafiada. A todo o momento os indivíduos estão em avaliação nos termos normativos que reconhecem seu comportamento como um sexo específico:

Quais são as consequências desta formulação teórica? Se, por exemplo, os indivíduos lutam para atingir o gênero, em encontros com outros, como uma cultura instila a necessidade de consegui-lo? Qual é a relação entre a produção de gênero, ao nível de interação, e tais arranjos institucionais como a divisão de trabalho na sociedade? $E$, mais importante, como "fazer gênero" contribui para a subordinação das mulheres pelos homens? (WEST; ZIMMERMAN, 1987 p. 140).

A compreensão etnometodológica foi estendida por West e Fenstermaker (1995, apud WEST; ZIMMERMAN, 2009) com o objetivo de se compreender como raça, gênero e classe operam simultaneamente entre si e com outras categorias. A diferença passou a ser conceituada em termos de um "fazer social", que se constitui num instrumento que organiza as relações presentes nas 
formas de dominação estabelecidas nas relações individual e institucional. Essas diferenças são criadas por meio das distinções das categorias de sexo, raça e classe, ainda que este caráter não é normal, natural ou essencial para aqueles que estabelecem as ligações.

A percepção metodológica do "fazendo gênero" inclui a análise da conversa, a observação sociológica, o autorrelato do informante, as análises das entrevistas não estruturadas, a análise dos diários, observações etnográficas e a verificação em arquivos (DULL; WEST, 1991 apud WEST; ZIMMERMAN, 2009; FENSTERMAKER, 1985 apud WEST; ZIMMERMAN, 2009; HERITAGE, 1984 apud WEST; ZIMMERMAN, 2009; KITZING, 2008 apud WEST; ZIMMERMAN, 2009; MOORE, 2001, 2002 apud WEST; ZIMMERMAN, 2009).

Já a teoria das características de status implica que o status atribuído é transformado em status alcançado. Este fato significa impulsionar a masculinidade e a feminilidade naturais, as particularidades essenciais dos indivíduos para o processo interacional, a fala, o social e as propriedades do sistema de relações. A constituição de gênero ocorre como imediatamente interacional e institucional, em razão do seu caráter imbuído nas relações sociais.

Há a possibilidade da ruptura da hegemonia de gênero, uma vez que ele está sujeito à mudança social. Esta construção de gênero é encontrada na esfera institucional na qual se desenrola. Embora a linha "teoria das características de status" também apresente uma análise interacional, sua metodologia consiste em laboratórios experimentais e as pesquisas estão em constante processo de ampliação e refinamento, cujo objetivo é verificar em quais momentos as mudanças e outras características de gênero ocorrem e são dinamizadas (WHARTON, 2005; WEST; ZIMMERMAN, 2009; SOUZA, 2010).

Finalmente, a homofilia compreende a atração-similaridade na constituição dos grupos conforme a categoria de sexo. A formação de cada grupo e das suas relações interpessoais, ou laços sociais, denota significado e apresenta impacto diverso, segundo os grupos específicos. Para a formação destes grupos é preciso considerar a dimensão sociodemográfica e considerar que tanto os homens quanto as mulheres tendem a participar de grupos com indivíduos do mesmo sexo. Esta característica da atração-similaridade interfere de forma decisiva na reprodução 
da desigualdade, pois cada pessoa terá o seu olhar e suas escolhas influenciadas pelos contextos e grupos em que está inserida (WHARTON, 2005; SOUZA, 2010):

Estas 'escolhas' influenciam na segregação, na alocação de profissionais no mercado de trabalho e na tendência de determinados estratos serem de característica tipicamente feminina e, por esta razão, contribuem para o aumento e a reprodução da desigualdade entre homens e mulheres. Este mesmo ponto que culmina em atitudes discriminatórias pode ser encontrado na vertente de status ou 'fazendo a diferença'. Como a categoria de sexo, as categorias de idade, raça e idade também estão na produção de similaridades ou dissimilaridades de grupos e indivíduos e no acesso desigual a poderes e a recursos (WHARTON, 2005, p. 52).

$\mathrm{Na}$ referência conceitual de gênero, outras autoras comungam da perspectiva interacional. Para Wharton (2005), a interação presente na organização e na rotina marca a vida social, organizando-a. A prática social está relacionada às organizações, principalmente no que concerne à construção e à reprodução da desigualdade e à diferenciação de gênero. Mas, é necessário ampliar o leque de análise para os indivíduos e, especialmente, as instituições, já que as mesmas são capazes de tecer um panorama mais fiel dos interstícios da vida social, se forem analisadas somente pelo espectro das organizações (SOUZA, 2010).

Nesta abordagem interacional, Wharton (2005) analisa o conceito de gênero. Ela, contudo, expande o conceito na operacionalização de outras duas escolas: a individual e a institucional.

Desta forma, a configuração de gênero passa a operar em três níveis: individual, interacional e institucional. No nível individual, embora haja discordâncias entre as escolas sobre o modo de ocorrência e a durabilidade das assimetrias, é senso comum que todos os indivíduos apresentem uma vida generada ${ }^{3}$. Já a interação se situa na produção das desigualdades na interação cotidiana, recorrente e por meio das relações sociais. No terceiro nível, o institucional, as discrepâncias de gênero são geradas pelos arranjos organizacionais e pelas instituições.

\footnotetext{
${ }^{3}$ Trata-se de palavra ainda não dicionarizada e nem elencada pelo VOLP - Vocabulário Ortográfico da Língua Portuguesa, documento ortográfico editado pela $\mathrm{ABL}$ - Academia Brasileira de Letras. Contudo, nesta condição de neologismo, o termo "generar" tem sido utilizado como um verbo e, nesta acepção, é tido como de "uso corrente", associado à ideia de "atribuir gênero a", variando em Língua Portuguesa, como variam os verbos regulares de primeira conjugação.
} 
Neste sentido, as práticas sociais não apresentam um modelo único de atividade: constituem-se modelos múltiplos e, conforme estas configurações das desigualdades, as práticas sociais são reproduzidas. O mundo social reflete, assim, de forma clara, o princípio de poder e gênero na vida social (SOUZA, 2010).

A reflexão a respeito do conceito de gênero como instituição social, sobretudo com as novas denotações conceituais de instituição, implica uma forma renovada de se pensar no comportamento de gênero, flertando com a possibilidade de mudança e de agregação de valor às mulheres nas diversas esferas da vida social (CONNEL, 1987; MARTIN, 2004).

\section{GÊNERO E INSTITUIÇÃO}

A proposta de Martin (2004) é a que analisa o conceito de gênero como uma instituição social. Compreender gênero como uma instituição, sob a ótica creditada por Martin, significa abranger críticas e perspectivas de uma sociabilidade profunda e torná-lo passível de uma mudança intencional, incluindo sua desconstrução (RISMAN, 2009).

Em seu artigo, "Gênero como instituição social" (2004), Martin apresenta diferentes análises referentes ao conceito de instituição. Primeiro, apresentam-se as vertentes e as mudanças dos séculos $\mathrm{XX}$ e $\mathrm{XXI}$ e, posteriormente, apresenta sua própria construção do termo.

No século $\mathrm{XX}$, as abordagens referentes à instituição, a caracterizavam como persistente, resistente e sem efemeridade no curso do tempo. As instituições apresentavam uma perspectiva macro social, sendo exteriores aos indivíduos, e podiam ser exemplificadas com a família, religião, educação, política e economia. Alguns analisavam a sociedade como um conjunto de instituições, necessárias, harmoniosas. Há autores que analisam o que é a instituição, outros, o que a instituição faz. Esta ainda é imbuída por qualidades morais e éticas (BERGER; LUCKMANN, 1966; BELLAH; COLLEAGUES, 1999; SEARLE, 1969, 1995 apud MARTIN, 2004).

A instituição era vista como aquela que controlava, capacitava e facilitava seus efeitos. Em meados do século XX, as instituições eram associadas a normas e a valores, mas, sob uma definição estática, sem processos e práticas que incluíam o 
individuo no processo de formação social. Entretanto, alguns pesquisadores indicavam conflitos inerentes às instituições:

\begin{abstract}
Nisbet criticou a definição de instituições feita pelos sociólogos, que ignorava as pessoas; representava cada instituição como separadas de todas as outras; sugeria um quadro a-histórico; descrevia as instituições como livres de conflitos, inconsistências, e mudanças, e falhava em considerar suas origens. Nisbet pediu mais atenção à agência (ao aspecto) humana (o) ao se criar e mudar as instituições sociais, e que os estudiosos estruturassem (considerassem) as instituições como se pejadas de conflitos, incoerências, e mudanças. Conflito dentro das bem como entre as instituições é pervasivo, ele argumentou (...) e esta dinâmica deveria ser explorada (ver Roscigno 2000, sobre dinâmica interinstitucional) (NISBET, 1953 apud MARTIN, 2004, p. 1254).
\end{abstract}

Martin (2004) ressalta que as escolas de gênero estiveram na vanguarda da dinâmica inclusiva das pessoas nas práticas e nas interações dos indivíduos que atuam e influenciam na constituição da instituição social. A autora reflete sobre as proposições dos teóricos contemporâneos, que veem as instituições como um conjunto de regras, costumes e rotinas capazes de transformação. Daí é que, autores como Giddens e Connell a apreendem em termos de repetição, costume e reprodução de práticas sociais.

Por sua vez, Acker se concentra nas práticas concretas e nos processos mobilizadores de gênero em vários caminhos, e Ridgeway aponta ligações nas crenças e nas práticas de gênero que culpabilizam (penalizam) as mulheres integrantes de movimentos sociais (GIDDENS, 1984 apud MARTIN, 2004; CONNEL, 1987 apud MARTIN, 2004; ACKER, 1992 apud MARTIN, 2004; RIDGEWAY, 2001 apud MARTIN, 2004):

Único entre os autores revistos até agora, Giddens considera o corpo e o empoderamento na dinâmica institucional, afirmando a significância dos corpos que existem materialmente e, consequentemente, fazem coisas, um tema desenvolvido posteriormente por Connell (...) em relação a gênero e sexualidade. As pessoas têm corpos que fazem coisas via ação física e comunicativa e, ao agirem, constituem a si mesmas na sociedade, com a estruturação referindo-se à constituição simultânea de "agentes" e "estruturas". Giddens reconhece as pessoas como atores situados, que, ativamente, constituem e reconstituem as instituições sociais e, ao fazer assim, sugere "de onde as instituições vêm", e 
como elas são mantidas, resistidas e mudadas (MARTIN, 2004, p. 1256).

Em face do cenário teórico apresentado, Martin (2004) elaborou doze critérios para caracterizar um fenômeno como instituição social: a) as instituições são profundamente sociais e são características de um grupo; b) as instituições resistem e persistem através de um tempo extensivo e de um espaço geográfico; c) as instituições requerem distintas práticas sociais que sejam recursivas (GIDDENS, 1984), sejam recicláveis (CONNELL, 1987) ou sejam frequentes (todo tempo) pelos grupos membros; d) as instituições constrangem e facilitam ações $e$ comportamentos pelos membros das sociedades/grupos; e) as instituições têm relações e posições pessoais que são caracterizadas pelas expectativas, papeis Inormas e procedimentos particulares; f) as instituições são constituídas e reconstituídas por agentes corporificados; g) as instituições são internalizadas pelos membros dos grupos como identidades e estes são apresentados como personalidades; h) as instituições têm uma ideologia legitimada; i) as instituições são inconsistentes, contraditórias e abundantes em conflitos; j) as instituições mudam constantemente; l) as instituições são organizadas de acordo com o poder e permeada por ele; e, $\mathrm{m}$ ) as instituições e os indivíduos se constituem mutuamente e não se separam dentro de fenômenos micro e macro (MARTIN, 2004; SOUZA, 2010).

Além destas características, Martin (2004) levanta dois pontos relacionados com as instituições sociais. O primeiro é a interdependência das instituições, gênero e família, gênero e trabalho, família e economia, por exemplo. As influências em diversas direções são mútuas e acontecem a todo o tempo.

Desta forma, as mudanças nas relações de gênero, no âmbito da segunda onda feminista, apresentam uma insegurança para determinadas instituições, como a família, o militarismo, a religião, entre outras instituições, devido às mudanças na legitimidade da subordinação de meninas e de mulheres.

O segundo aspecto é o de que as instituições são entrelaçadas com o Estado. Este apresenta poder sobre outras instituições quando elas codificam práticas particulares na Lei e reforça, por exemplo, a polícia, o militarismo e, informalmente, a retórica, e ajuda a construir o interesse da nação e a ideologia. 
"Attempts to understand gender without taking into account the state/polity and other institutions will produce flawed results, as will any attempt to understand other institutions without taking gender into account" ${ }^{4}$ (2004, p. 1259).

Estudos como os de Wharton (2005) buscaram compreender a mudança social presente nos processos sociais extremamente institucionalizados como o de gênero. Este esforço intelectual produziu dois conhecimentos-chaves dignos de nota, pois são considerados relevantes para a redução da desigualdade entre mulheres e homens. Concluiu-se que as relações sociais altamente institucionalizadas não são passíveis de imunidade, pois a mudança social é inevitável e contínua, em um crescimento de viés diversificado no mundo.

Além da onipresença da mudança social, pode-se compreender que esta modificação quase nunca ocorre da mesma maneira. $\mathrm{Na}$ maioria das vezes é desigual e seus impactos, no tempo e no espaço, abrangem efeitos diferenciados. Esta mudança "cria conflito, tensão, e ruptura, o que tem, às vezes, inspirado tentativas de mais longo alcance e mais conscientes, para se alterar os arranjos institucionalizados" (WHARTON, 2005, p. 226).

\section{INSTITUIÇÃO, STATUS DE GÊNERO E TRABALHO}

As normas sociais ocasionam consequências acentuadas na análise relacionada à maneira de agir do ser humano. Os seres humanos são compreendidos diversamente segundo a legibilidade da raça, a reconhecibilidade da morfologia, a comprovação perceptual do que é o sexo e a compreensão categórica referente à etnia. Com os signos sociais avaliados, alguns indivíduos são aquinhoados com maior relevância social do que os demais, não reconhecidos socialmente em sua plenitude. Em particular, estas últimas pessoas citadas apresentam uma vida social inviável e participam de uma ordem de vida inabitável. O reconhecimento muitas vezes implica na construção ou na desconstrução do outro, momento em que o indivíduo é pensando diferencialmente e assimetricamente (BUTLER, 2004).

\footnotetext{
${ }^{4}$ Tradução livre da autora: "Tenta compreender o gênero sem levar em conta o sexo ou como o Estado e outras instituições o compreendem, ainda que se produzam resultados imperfeitos em tal compreensão".
} 
As contínuas construção e reconstrução das assimetrias entre as categorias de gênero são explicadas por Lorber e Farrel (1991) como parte de uma estrutura inserida em um grupo social relacional entre dominação e subordinação, divisão do trabalho na economia e na família.

A categoria de gênero é situada como um dos maiores, senão o maior, status social, pois é o formador de oportunidades para o indivíduo, como nas áreas da educação, do trabalho, da família, da autoridade e com influência sobre a produção da cultura e do conhecimento.

Cada sociedade corresponde a uma extensão da desigualdade entre homens e mulheres. Se ocorrer a desigualdade, entretanto, as mulheres são essencialmente desvalorizadas $e$ alocadas em postos de trabalho também desvalorizados.

A pesquisadora Lorber (1994), apresentou a seguinte proposta para a construção do status de gênero: a) posição social ou status de gênero; b) divisão do trabalho generado; c) parentesco generado; d) "documento" sexual generado; e) personalidades generadas; f) controle social generado; g) ideologia de gênero; e, h) imagem de gênero.

Instituições de controle social denotam homens e mulheres de forma diferenciada e, na maioria das vezes, conferindo o poder aos homens, excluindo aqueles que fazem parte de grupos sociais étnicos raciais e os da classe trabalhadora. Mulheres são alocadas em grupos de desvantagem e estão sujeitas a um maior controle social.

Os homens ou as mulheres presentes em categorias com maior acesso aos recursos produtores de alto valor e ao bem-estar detêm mais poder e propriedade se comparados aos membros de categorias menos favorecidas. Mas, em todas as categorias sociais, os homens estão em vantagem em relação às mulheres. Um dos destaques realizados por Lorber e Farrel (1991) é que, ironicamente, em grupos étnicos raciais com menos recursos, ambos os sexos tendem a ser mais simétricos do que nos grupos étnicos em que a distribuição de riqueza é diferencial. Se há um acesso reduzido à educação, à saúde, às oportunidades de emprego e ao poder político, o quê os homens poderão controlar?

Como na análise de Butler (2004), Lorber e Farrel (1991) também se situa gênero como elemento relacionado com as outras categorias construídas 
socialmente, tal como o conceito de raça. As categorias de "raça, etnia e classe social" são institucionalizadas como parte de um status cultural e social. São estes status ou localizações sociais que formam o indivíduo desde o nascimento. Os comportamentos em torno desta constituição não são apenas de ordem sexual ou procriativa, mas, também, psicológica, física, identitária, e são influenciados pela localização de classe, grupo étnico racial e categoria de gênero.

Deve-se acrescentar que, mesmo havendo uma tendência à homogeneização analítica, em relação à raça, etnia e, em alguns casos, status econômico, as sociedades não deixaram de considerar gênero como um importante fator de divisão social. A separação do mundo social entre homens e mulheres é essencialmente enraizada durante a vida, desde o nascimento, momento no qual as pessoas em volta "constroem o gênero" do recém-nascido, a começar pela escolha do nome.

Atendo-se às relações de gênero no âmbito da classe, conforme indicam os estudos de Wright (2001), há uma confirmação empírica de que estas opressões de classe e de gênero podem variar, uma independente da outra, e que ambas refletem e influenciam, de modo notório, na construção de uma estrutura social. Entretanto, as pesquisas mostraram, ainda, o comportamento de gênero e de classe como interações causais mútuas capazes de provocar efeitos no extenso raio social e que constituem um especial interesse de análise - o que pode levar a se pensar no conceito "Clender". É no âmbito da "vida vivida" que estes conceitos se incorporam e demonstram os conflitos das relações e o empoderamento de gênero que emerge em diversas esferas sociais, em especial, no mercado de trabalho.

As análises apresentadas fazem coro ao avanço feminino na vida social, no que se refere à capacidade de transformação através dos contínuos processos interacionais nas relações sociais ou nos arranjos institucionais. Entretanto, Butler (2004) ressalta a necessidade de uma urgente emancipação das mulheres, uma vez que não é possível afirmar o fim ou a superação quase total do preconceito na sociedade impulsionada pela divisão sexual:

\footnotetext{
${ }^{5}$ Expressão provavelmente derivada do vocábulo “calender" (ao pé da letra, traduzindo do inglês: 'calendário'). Nos estudos socio-antropológicos contemporâneos, a expressão "clender" tem-se associado ao fato de que "homens pegadores" fazem a sua "contabilidade" sexual, atribuindo pontos para os seus sucessos de conquista sexual e ou amorosa.
} 
Bem, eu certamente não acho que estamos vendo o fim da discriminação econômica contra a mulher, não acho que vimos o fim da desigualdade ou da hierarquia de gênero. Não acho que vimos 0 fim da violência contra a mulher, não acho que vimos o fim de certas concepções profundamente arraigadas sobre quais são as fraquezas das mulheres ou sobre a capacidade das mulheres na esfera pública, ou sobre uma série de outras coisas. Portanto, essas lutas ainda estão muito vivas [...]. Se a gente olha para diferentes níveis de pobreza, diferentes níveis de escolaridade, vê que o sofrimento das mulheres é incomensurável (BLUTER, 2004, p. 162).

As 'lutas muito vivas', às quais Butler (2004) faz coro, são presenças também vivas e urgentes nas práticas sociais das mulheres ávidas por transitar no mundo do trabalho, da família e das relações de poder. O mundo do trabalho se apresenta fundamental para se compreender as lutas e as resistências das mulheres, pelo fato de invocar um amplo significado social que denota poder, dinheiro, autoestima, interesses e condução das relações familiares. A presença feminina na esfera laboral a conduz para a independência econômica, a chefia da família, a voz atuante na esfera pública e a dignificação da pessoa humana.

\section{O CONCEITO DE GÊNERO COMO ESTRUTURA SOCIAL}

Risman (2004), por sua vez, apresenta o conceito de gênero como uma estrutura social presente na vida do indivíduo. A elaboração conceitual é organizada de forma integrativa com as demais interpretações de gênero na tradição das Ciências Sociais.

O primeiro pilar desta tradição baseia-se em estudos como os de Bem (1981, 1983) e Udry (1994). Nesta abordagem, a construção de gênero apresenta raízes individuais e biossociais. A perspectiva de Sandra Bem, teoria "gender schema" (concebida como uma teoria cognitiva por Bem, em 1981, explica como os indivíduos se tornam sexuados na sociedade e como as características ligadas ao sexo são mantidas e transmitidas a outros membros de uma cultura), integra um corpo de análise na teoria psicológica do desenvolvimento na contribuição do "sex typing" (aquisição e a apropriação de conhecimento das pessoas, em especial, das crianças, conforme as preferências de sexo, capacidades, comportamentos, atributos da personalidade e autoconhecimento). 
Três teorias integram este quadro. A psychoanalytic theory; a social learning; e, a cognitive-developmental theory. Bem apresenta uma quarta teoria, com base no sex typing, não situada no universo da psicologia, para tentar compreender este processo cognitivo de formação do indivíduo: a gender schema theory.

Esta teoria de Bem propõe que o sex typing é resultado, em parte, do processo esquemático baseado em gênero, donde deriva uma generalizada aptidão para a dinâmica de informação sobre a base da associação na sex-linked que constituem o esquema de gênero.

Conforme Bem (1981, p. 355), "A schema is a cognitive structure, a network association that organizes and guides an individual's perceptions" (tradução livre da autora: "Um esquema é uma estrutura cognitiva, uma associação de rede que organiza e orienta a percepção do indivíduo").

Um esquema funciona antecipadamente à estrutura, é uma habilidade para conhecer e assimilar informações em termos relevantes. Desta forma, o processo esquemático é altamente seletivo e torna o indivíduo apto a conferir significado a uma vasta gama de conhecimentos e de formação da personalidade, conforme uma determinada cultura (BEM, 1981; 1983).

Já a proposta de Udry (1994) é a de apresentar um modelo biossocial de comportamento generado da mulher, cujo modelo integra uma teoria macrossociológica com uma teoria proveniente do comportamento primata. 0 pesquisador realiza algumas considerações pontuais em relação à concepção de gênero como uma estrutura social: a) para ele, este fato não implica, obrigatoriamente, em normas comportamentais generificadas; b) normas de gênero podem ser resultados, mas não consequências, das diferenças entre os sexos; c) a estrutura social generificada não é evidência da discriminação entre os sexos; d) a socialização da família pode apresentar pouca influência nas distinções do comportamento generificado; e, e) se os demógrafos e os cientistas sociais não aceitam a relação entre a biologia e os seus modelos analíticos, eles deverão fazer uma análise macrossocial.

Entretanto, Udry demonstra a importância de se realizar este entrelaçamento da biologia do gênero com as pesquisas das Ciências Sociais (fundamentos da primeira tradição) e verificar como ela pode ser integrada. 
A segunda tradição apresenta o comportamento de homens e mulheres conforme o resultado de fatores sociais, como a socialização e o controle social. Ela é um contraponto à primeira tradição. Um dos grandes nomes é o de Epstein (1998). Um aspecto importante é que a pesquisadora demonstra como nos registros antropológicos das sociedades antigas havia uma igualdade maior entre homens e mulheres.

Os papeis sociais eram menos rígidos e não havia tantos estereótipos, embora os status fossem separados, os papeis eram mais similares. Outro aspecto é que os trabalhos alocados estão associados não à biologia, mas aos arranjos sociais. A divisão sexual do trabalho é determinante para privilegiar os homens e, comumente, as Leis e as informações a aplicam e, sob a restrição desta barreira, as atividades dos homens e das mulheres podem ser equiparadas.

É comum que as organizações guiem seus parâmetros de relacionamento de gênero de forma implícita. Assim, não é possível perceber sob quais aspectos há a distribuição de poder e recursos. As práticas sociais, nestas culturas organizacionais institucionalizadas, estão reproduzindo naturalmente as assimetrias de gênero nos acessos às oportunidades e ao bem-estar nos trabalhos realizados.

A socióloga Epstein exemplifica ainda com o aumento das taxas de crime cometidas por mulheres em todo mundo, o que demonstra que não são os ditames biológicos que determinam este tipo de comportamento, mas, sim, os fatores sociais. Embora comportamentos humanos restritos tenham causas biológicas, ainda sim, elas são limitadas pela reprodução ou por diferenças no corpo da estrutura (EPSTEIN, 1998; GUEDES, 1995; RISMAN, 2004).

A terceira tradição, também propõe um afastamento da primeira tradição, reflete gênero como a interação das relações sociais, na prática cotidiana, na proposta interacionista referendada por West e Zimmerman (1991, 2009).

A quarta tradição é a abordagem integrativa, e implica em um sistema de estratificação socialmente construído e deve estar no mesmo nível de análise das estruturas políticas e econômicas. Como precursores desta fase, há Risman (1998), Lorber (1994) e Connell (2002).

Considera-se neste ponto que a teoria da estruturação de Giddens (1982) acrescenta fundamentos consideráveis à análise de gênero, tido como uma estrutura social enfática na relação social recursiva entre estrutura e indivíduo. Através dessa 
teoria da estruturação, Giddens procurou estabelecer um diálogo entre as diferenças da estrutura e da ação e acaba com o império estabelecido entre ambas. Estes distanciamentos são de ordem epistemológica, mas, também, ontológica:

O domínio básico de estudo das ciências sociais, de acordo com a teoria da estruturação, não é a experiência do ator individual nem a existência de qualquer forma de totalidade social, mas as práticas sociais ordenadas no tempo e no espaço (GIDDENS, 1982, p. 03; RISMAN, 2004).

Neste aspecto, Risman (2004) considera que a preocupação da agenda consiste em saber por quais razões os atores escolhem determinada opção de vida e esta justificativa, segundo Giddens (1982), deve estar além da justificação verbal, pois muito da vida social é rotina e é considerada como certa pelos indivíduos que não se articulam e também não consideram o porquê de atuar.

Esta não reflexividade é considerada por Risman como um componente cultural da estrutura social. Ela implica em ações consideradas corretas e as regras da imagem cognitiva presentes no contexto situacional e não apenas para delinear a personalidade do ator. $O$ componente cultural inclui a expectativa que nós apresentamos nos encontros sociais.

Para Risman (2004), é importante conceituar gênero como uma estrutura social, pois este caminho permite investigar sob quais condições e em que dimensão a desigualdade de gênero é produzida. A fim de se realizar uma intervenção sobre os processos de assimetria, deve-se saber o como eles ocorrem e os mecanismos que os tecem.

Risman (2004) explica a impossibilidade de se encontrar um quadro teórico universal, já que as leis sociais universais foram uma ilusão do empirismo do século XX. Em um determinado momento e em um contexto específico, os processos causais devem ser identificáveis empiricamente e de forma particular. A complexidade de gênero ultrapassa qualquer tentativa de generalização histórica.

Há, contudo, alguns processos particulares causais que se restringem a uma dimensão de gênero mais forte em uma configuração institucional (em casa) e mais fraca em outra dimensão (no trabalho). É importante compreender que o tradicionalismo de gênero é construído de forma diferenciada no tempo e no espaço. 
E, para Risman (2004), os processos causais têm a probabilidade de serem efetivos em cada uma dessas dimensões.

Ao se avaliar a dimensão de gênero, em uma esfera interacional/cultural, os caminhos pelos quais as diferenças de status formam as expectativas e os caminhos entre os grupos e dentro dos grupos, conclui-se que eles influenciam necessariamente o comportamento e também se tornam um centro importante de análise. É empreendida uma crítica ao se explicar que pouca atenção é direcionada à compreensão de como a desigualdade é formada por cada experiência cultural durante a interação (RISMAN, 2004).

A dimensão institucional se situa nas leis, nas práticas organizacionais e nas regulações formais que diferenciam a categoria de gênero. Os avanços em prol da equidade foram realizados na geração dos direitos civis, com a adequação de Leis e práticas organizacionais que ensejam a neutralidade de gênero.

Outro ponto criticado pela autora é o de que, embora haja mudanças referentes à socialização dos meninos e das meninas no âmbito da dimensão institucional, ainda persistem os vestígios da estratificação de gênero. A proposta de Risman (2004) é compreender gênero nesta complexidade e buscar isolar os processos sociais que o criam em cada dimensão. Isso permite refletir sobre o como se podem alterar estes processos e transformar os caminhos nos quais se constrói, socialmente, o gênero.

Outro aspecto situado pela autora é o de que as desigualdades de gênero podem estar relacionadas especialmente às expectativas interacionais em um plano cultural. Risman (2004) explica que a revolução de gênero estagnada em algumas configurações pode ser relacionada à dimensão interacional/cultural da estrutura social.

Embora as mulheres e os homens que possuam o discurso feminista se insiram em organizações maduras para práticas de mudança e com regras formais de gênero neutro, a desigualdade de gênero é reproduzida ao longo da interação cotidiana. A perspectiva cultural inerente à categoria de sexo, quando identificado simplesmente como homem ou mulher, é, em muitos aspectos, impenetrável para o estudo feminista, que colocou no centro do debate as práticas de socialização sexista e a discriminação legal (Quadro 01). 
Quadro 01 - Dimensões da estrutura de gênero, pela explicação do processo social

\begin{tabular}{|c|c|c|c|}
\hline & \multicolumn{3}{|c|}{ DIMENSÕES DA ESTRUTURA DE GÊNERO } \\
\hline & $\begin{array}{l}\text { Interacional } \\
\text { Individual }\end{array}$ & $\begin{array}{c}\text { Nível da } \\
\text { expectativa } \\
\text { Cultural }\end{array}$ & $\begin{array}{c}\text { Domínio } \\
\text { Institucional }\end{array}$ \\
\hline Processo Social & $\begin{array}{c}\text { Socialização } \\
\text { Internalização }\end{array}$ & $\begin{array}{c}\text { Expectativa de } \\
\text { status }\end{array}$ & $\begin{array}{c}\text { Práticas } \\
\text { Organizacionais }\end{array}$ \\
\hline & $\begin{array}{c}\text { Identidade de } \\
\text { trabalho } \\
\text { Construção de } \\
\text { identidades }\end{array}$ & $\begin{array}{c}\text { Propensão } \\
\text { cognitiva } \\
\text { Othering } \\
\text { Trading power for } \\
\text { patronage } \\
\text { Altercasting }\end{array}$ & $\begin{array}{l}\text { Regulações legais } \\
\text { Distribuição de } \\
\text { Recursos } \\
\text { Ideologia }\end{array}$ \\
\hline
\end{tabular}

Fonte: Risman (2004).

Nota: Estes exemplos de processos sociais são apresentados por Risman na tentativa de explicar a estrutura de gênero em cada dimensão, embora sejam ilustrativos e não esgotem os processos sociais possíveis e os mecanismos causais (2004, p. 437).

A abordagem proposta por Risman (2004) demonstra que a reflexão essencial nos estudos de gênero é a de pensar quais são os mecanismos construtores da desigualdade e por quais caminhos estes instrumentos podem ser modificados a fim de criar um mundo mais justo.

Como críticos e pesquisadores, é preciso estudar o gênero com o intuito de vislumbrar a estrutura desigual de gênero em um movimento de transformação. Além de estudar as assimetrias, deve-se pensar na melhoria da mulher, na transformação social e na questão da agência.

Os grupos subordinados se reúnem para a mobilização? Em qual momento? Os grupos superiores se mobilizam contrariamente àqueles? Como é possível compreender e identificar os processos de agência?

Risman (2004) explica a necessidade de se compreender o como e o porquê gênero é feito, independentemente de ser consciente ou não, para oferecer caminhos aos indivíduos que pretendem mudar a postura socialmente discriminatória:

Se nós podemos identificar os mecanismos que criam gênero, talvez nós possamos oferecer alternativas para eles e então usar nosso trabalho de pesquisa para contribuir para a construção de uma utopia feminista (p. 447). 
Como o gênero não se constitui sozinho, mas em relação com o outro, mesmo sendo este outro imaginário, a normatização da vida social pode implicar em um número de mulheres vivendo em condições precárias, inclusive no mundo do trabalho. As normas sociais constituem a existência do indivíduo e tentam implantar desejos que não fazem parte da personalidade individual, assim, a personalidade se torna fundamentalmente ligada às normas sociais.

Conforme a tradição hegeliana, o desejo é sempre um anseio de reconhecimento e é através desta experiência do reconhecimento que o indivíduo se torna um ser socialmente viável. Caso não se possua este reconhecimento social, a convivência e a participação se tornam mais difíceis, com a exclusão e as formas diversas de desigualdade. A norma pode implicar na distorção do reconhecimento de si, mas, também, do outro (BUTLER, 2004).

\section{CONSIDERAÇÕES FINAIS}

Pôde-se verificar na leitura das abordagens que, independentemente das linhas teóricas aqui discutidas, a desigualdade ente homens e mulheres, particularmente no que tange ao acesso aos recursos produtos ou produtores socioculturais de alto valor ainda resistem.

Ao lado disso, caminham celeremente as desiguais oportunidades sociais de bem-estar, sob as quais o cenário de reprodução social se amplia nos meios institucionais ou interacionais.

Um ponto de reflexão sobre esta contingência é a possibilidade de uma dinamização nas disposições de desigualdade de gênero, a partir da ruptura e da estratégia de superação em ambas as análises. $\mathrm{Na}$ análise "Institucional", gênero é visualizado como uma instituição passível de transformação. No âmbito "Institucional", a formação de identidades, comportamento e escolhas de ambos os sexos poderá ser forjada na perspectiva contrária à subjacência do grupo feminino ao grupo masculino.

Assim, em uma proposta de emancipação, a linha "Gênero como estrutura social", situa a urgência de compreender as causalidades da reprodução da desigualdade de gênero para viabilizar a ação efetiva de pesquisadores, discentes e organizações sociais, de uma forma geral. 
Além disso, uma das questões que envolvem a problemática da mulher no mercado de trabalho está relacionada com uma concepção normativa de gênero capaz de inferir no reconhecimento da mulher nas várias dimensões que a vida comporta, na construção do seu self e na capacidade de sobrevivência e perseverança em uma vida de fato vivível.

\section{REFERÊNCIAS}

BEM, Sandra Lipsitz. Gender Schema Theory and its implications for child development: raising gender-aschematic children in a gender-schematic society. Signs. Chicago: The University of Chicago Press, v. 8, n. 4, p. 598-616, 1983.

BEM, S. L.; ANDERSEN, S. M. Sex typing and androgyny in dyadic interaction: Individual differences in responsiveness to physical attractiveness. Journal of Personality and Social Psychology, n. 41, p.74-86, 1981.

BUTLER, Judith. Undoing gender. New York: Routledge, 2004.

Problemas de gênero: feminismo e subversão da identidade. 3. ed. Rio de Janeiro: Civilização Brasileira, 2010.

CONNELL, Robert William. Gender and power: society, the person, and sexual politics. Stanford: Stanford University Press, 1987.

. Gender. Cambridge, UK: Polity Press, 2002.

EPSTEIN, Cynthia Fuchs. Deceptive distinctions: sex, gender and the social order. New Haven, CT: Yale University Press, 1998.

GIDDENS, Anthony. Sociology. A brief but critical introduction. London: Macmillan, 1982.

. A constituição da sociedade. Cambridge: Polity, 1984.

GUEDES, Maria Eunice Figueiredo. Gênero: o que é isso? Psicologia: Ciência e Profissão, Brasília, v. 15, n.1-3, p. 4-11, 1995.

Disponível em: <http://pepsic.bvsalud.org/scielo.php?pid=S141498931995000100002\&script=sci_arttext> Acesso: 12 jan, 2014.

LORBER, Judith; FARRELL, Susan. The social construction of gender. Newbury Park: Sage, 1991.

LORBER, Judith. Paradoxes of gender. New Haven, CT: Yale University Press, 1994. 
MARTIN, Patrícia. Gender as social institution. Louisiana: Southern Sociological Society, 2004.

RISMAN, Barbara. Gender as a social structure - Theory arestling with Activism. Gender \& Society, v. 18, n. 4, p. 429-450, 1994.

. Gender vertigo: American Families in Transitioin. New Haven, CT: Yale University Press, 1998.

. Gender as social structure: Theory wrestling with activism. Gender \& Society, n. 18(4), p. 429-450, 2004.

2009.

From Doing to Undoing Gender. Gender \& Society, n. 23(1), p. 81-84,

SOUZA, Marcela Fernanda da Paz de Souza. Estrutura social, inserção feminina e efeitos na renda no Brasil. (Dissertação de mestrado). Programa de Pós-Graduação em Ciências Sociais. Universidade Federal de Juiz de Fora, 2010.

WEST, Candace; ZIMMERMAN, Don. Doing gender. Gender \& Society, v. 1 n. 2, p. 125-151, 1987. Disponível em: <http://gas.sagepub.com/content/1/2/125.abstract>. Acesso em: 14 jan. 2013.

WEST, Candace; ZIMMERMAN, Don. Doing Gender. In: LORBER, Judith; FARRELL, Susan (Ed.). The social construction of gender. London: Sage, 1991. p. 13-37.

WEST, C.; ZIMMERMAN, D. H. Accounting for doing gender. Gender \& Society, v. 23, n. 1, p. 11-122, 2009. rizisponível em: <http://gas.sagepub.com/content/23/1/112.extract>. Acesso em: 14 jan. 2013.

WHARTON, Amy. The sociology of gender: an introduction to theory and research. Oxford: Blackwell, 2005.

WRIGHT, Erik Olin. A conceptual menu for studying the interconnections of class and gender. In: BAXTER, J.; WESTERN, M. (Ed.). Reconfigurations of class and gender. Stanford: Stanford University Press, 2001. Disponível em: < http://www.ssc.wisc.edu/ wright>. Acesso em: 09 jul. 2009. 